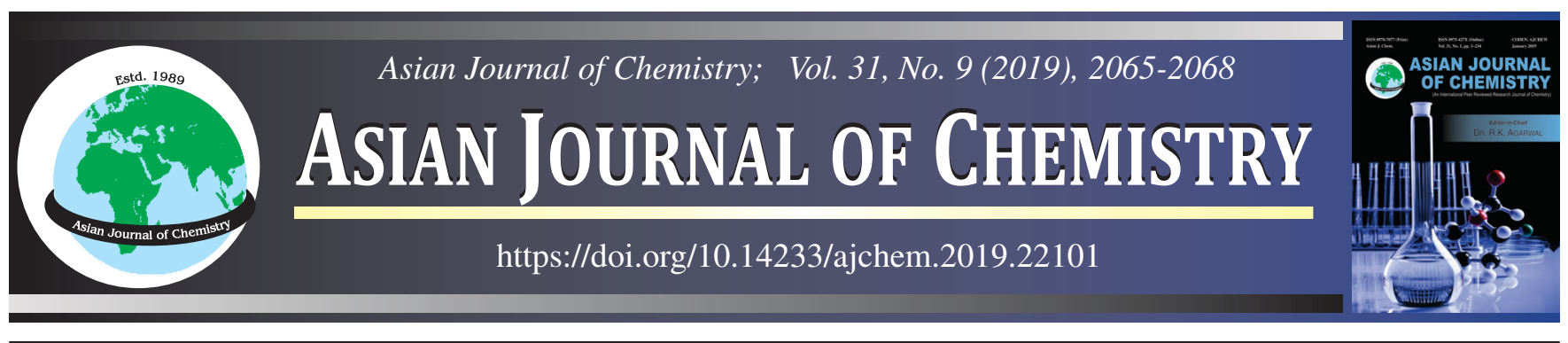

\title{
Effective Utilization of Algae Biomass from Wastewater for Biodiesel Production by Direct Transesterification: A Promising Approach for Sustainable Bioenergy Production
}

\section{P. Nautiyal ${ }^{1,2, *}$, K.A. Subramanian ${ }^{1}$, M.G. Dastidar ${ }^{1}$ and A. Kumar ${ }^{1,3}$}

${ }^{1}$ Centre for Energy Studies, Indian Institute of Technology Delhi, New Delhi-110016, India

${ }^{2}$ Department of Chemistry, New Horizon College of Engineering, Bengaluru-560103, India

${ }^{3}$ Department of Mechanical Engineering, New Horizon College of Engineering, Bengaluru-560103, India

*Corresponding author: E-mail: piyushi.nautiyal@gmail.com

Received: 28 March 2019;

Accepted: 3 May 2019;

Published online: 31 July 2019;

AJC-19498

Currently, biodiesel produced from algae is receiving a positive response as a substitute for conventional base diesel. To cope up from the costs of expensive downstream stages in the production of biodiesel from algae, present investigation is conducted using algae growing in wastewater as lipid source for biodiesel production. The in situ transesterification using algae was carried to optimize the effect of reaction parameters on the biodiesel yield. The parameters studied were: temperature $\left(35-75^{\circ} \mathrm{C}\right)$, algae biomass (wt.) to methanol (vol.) ratio (1:11:6), catalyst concentration (25-100 wt. \%) and stirring intensity (150-750 rpm). The optimum conditions for maximum biodiesel yield achieved were: catalyst concentration and algae biomass to methanol ratio were $60 \%$ and 1:4, respectively with stirring intensity of 450 $\mathrm{rpm}$ at $55^{\circ} \mathrm{C}$. The gas chromatographic studies and fuel properties of biodiesel also establish its potential to be used as fuel in existing engines in accordance to American and European standards.

Keywords: Algae, Biodiesel, Transesterification, Wastewater, Biofuel.

ᄂ - - - - - - - - - - - - - - - - - - - - - - - - - - - - -

\section{INTRODUCTION}

Due to depletion as well as increased consumption of fossil fuels, the biodiesel from non-edible sources is gaining significance [1]. Biodiesel is basically comprised of fatty acid alkyl esters (FAMEs) derived from plant or animal origin, which are considered to be cleaner, renewable, carbon neutral and biodegradable $[2,3]$. Some of the edible oil seed crops which are used for biodiesel production include palm, soybean, rapeseed, sunflower, coconut, etc. [4,5]. The use of edible sources for biodiesel production has caused the worldwide food threat which is a serious matter of concern. Therefore, raw materials like jatropha, karanja, mahua, jojoba, microalgae, etc. being non-edible sources are more actively used for biodiesel production [6,7].

Microalgae have gained attention in the current years as the biodiesel feedstock because of their rapid biomass production, high lipid content and adaptation to any kind of growing medium [8,9]. The common method to produce biodiesel involves steps like oil extraction, purification and finally the transesterification. This method can be replaced with simultaneous oil extraction and transesterification of algae oil to biodiesel, which can reduce the overall biodiesel production time and its cost, thus making it economically viable process. As the use of microalgae is a new area for biodiesel production, not much literature is available regarding this. The works on optimization of simultaneous oil extraction and transesterification of algae oil are also scarce. Algae have emerged as one of the prospective feedstock for production of biodiesel; nevertheless, the optimization of biodiesel production via simultaneous extraction and transesterification from pond water algae has not been done yet. The present study deals with optimization of experimental conditions of simultaneous oil extraction and transesterification of pond water algae biomass in order to obtain the maximum biodiesel yield. The study was conducted to investigate the effect of reaction parameters (reaction temperature, methanol volume, catalyst volume, stirring intensity) on the biodiesel yield.

\section{EXPERIMENTAL}

The algae biomass was collected from pond located near India Gate in New Delhi, India. All the reagents and chemicals

This is an open access journal, and articles are distributed under the terms of the Attribution 4.0 International (CC BY 4.0) License. This license lets others distribute, remix, tweak, and build upon your work, even commercially, as long as they credit the author for the original creation. You must give appropriate credit, provide a link to the license, and indicate if changes were made. 
used in the investigation i.e. methanol, hexane, sulphuric acid (98\% pure) were procured from Merck of analytical grade.

Experimental procedure: The algae biomass was sundried and then exposed to cell disruption using mechanical pulverization. The singe-stage in situ transesterification of algae in a batch reactor was attempted. The known amount of dried biomass and the known volume of methanol (reactant) and conc. $\mathrm{H}_{2} \mathrm{SO}_{4}$ (catalyst) were added to the reactor coupled with a magnetic stirrer and reflux condenser. The solvent (hexane) was also added to the reactor. The reactants in the reactor were stirred using magnetic stirrer at a definite intensity and temperature. After the completion of reaction, the contents of reactor were allowed to cool down and then transferred to the separating funnel. The contents were washed with warm distilled water and then allowed to form two immiscible layers. The upper layer constitutes the biodiesel along with the solvent which was carefully separated from the lower layer. This lower layer comprised mainly of excess methanol, catalyst, water and glycerol. The biodiesel was then separated from the solvent via simple distillation. The percentage yield of algae biodiesel obtained was calculated using eqn. 1:

Yield of algae biodiesel $=\frac{\text { Weight of biodiesel obtained }(\mathrm{g})}{\text { Oil taken }(\mathrm{g})} \times 100$

Therefore, using above procedure, the batch experiments were performed in order to identify the optimum reaction parameters required to achieve the maximum yield of biodiesel. The reaction parameters were accordingly: temperature (35 ${ }^{\circ} \mathrm{C}$ to $75^{\circ} \mathrm{C}$ ), algae biomass (wt.) to methanol (vol.) ratio (1:1 to $1: 6$ ), catalyst concentration (25-100 wt. \%) and stirring intensity (150 to $750 \mathrm{rpm}$ ).

\section{RESULTS AND DISCUSSION}

The methyl esters of fatty acids present in biodiesel (Table1) produced from wastewater algae biomass were mainly of palmitic acid (38.39\%) followed by linoleic acid (5.53\%), linolenic acid (3.25\%), oleic acid (11.73\%), caprylic acid $(3.76 \%)$ and myristic acid $(3.33 \%)$ [10]. The fuel properties of produced algae biodiesel are reported in Table-2 satisfied benchmarks as prescribed by American and European standards with density of $872 \mathrm{~kg} / \mathrm{m}^{3}$ and viscosity of $5.82 \mathrm{~mm}^{2} / \mathrm{s}$ [11]. The calorific value obtained for biodiesel was found to be 40.8 $\mathrm{MJ} / \mathrm{kg}$ which were lower than $43.23 \mathrm{MJ} / \mathrm{kg}$ of diesel but higher than $40.44 \mathrm{MJ} / \mathrm{kg}$ of karanja biodiesel and $39.28 \mathrm{MJ} / \mathrm{kg}$ of tallow biodiesel.

Effect of reaction temperature: The effect of temperature on biodiesel yield from wastewater algae biomass is shown in Fig. 1. The reaction was carried for the total time duration of $60 \mathrm{~min}$ while varying the temperature of reactor from 35 to $75^{\circ} \mathrm{C}$. This temperature range was carefully chosen

TABLE-1 COMPOSITION OF ALGAE BIODIESEL

\begin{tabular}{lc}
\hline \multicolumn{1}{c}{ Detected compound } & Weight $(\%)$ \\
\hline Palmitic acid methyl ester & 38.39 \\
Linolenic acid methyl ester & 3.25 \\
Linoleic acid methyl ester & 5.53 \\
Oleic acid methyl ester & 11.73 \\
Caprylic acid methyl ester & 3.76 \\
Myristic acid methyl ester & 3.33 \\
\hline
\end{tabular}

TABLE-2

FUEL PROPERTIES OF ALGAE BIODIESEL

\begin{tabular}{lccc}
\hline \multicolumn{1}{c}{ Property } & $\begin{array}{c}\text { Algae } \\
\text { biodiesel }\end{array}$ & $\begin{array}{c}\text { ASTM } \\
\text { D6751 }\end{array}$ & $\begin{array}{c}\text { EN } \\
14214\end{array}$ \\
\hline Density $\left(\mathrm{kg} \mathrm{m}^{-3}\right)$ at $25^{\circ} \mathrm{C}$ & 872 & - & $860-900$ \\
Specific gravity $(\mathrm{g} / \mathrm{mL})$ at $25^{\circ} \mathrm{C}$ & 0.878 & 0.88 & - \\
Viscosity $\left(\mathrm{mm}^{2} / \mathrm{s}\right)$ at $40{ }^{\circ} \mathrm{C}$ & 5.82 & $1.9-6.0$ & $3.5-5.0$ \\
Calorific value $(\mathrm{MJ} / \mathrm{kg})$ & 40.80 & - & - \\
Acid value $(\mathrm{mg} \mathrm{KOH} / \mathrm{g})$ & 0.40 & $0.50 \max$ & $0.50 \max$ \\
\hline
\end{tabular}

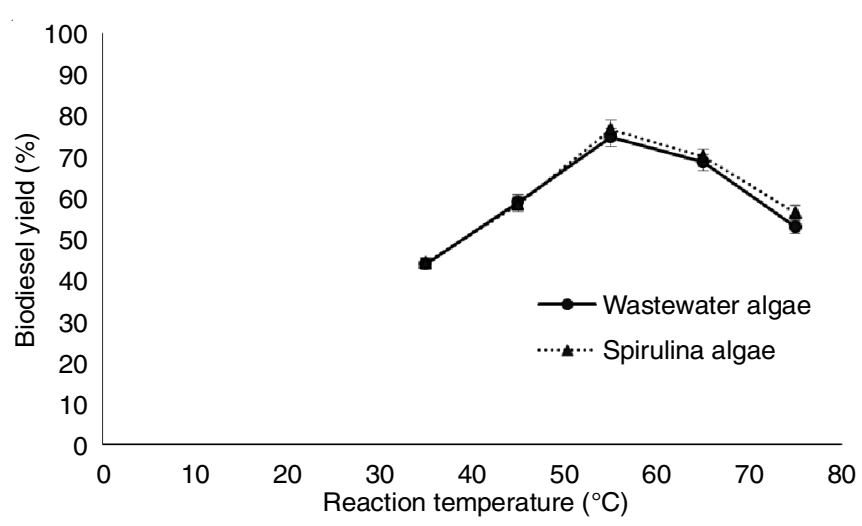

Fig. 1. Effect of reaction temperature on yield of biodiesel from algae [450 rpm stirring intensity, $60 \mathrm{wt}$. \% concentration of catalyst, 1:4 algae biomass:methanol (wt:vol)]

depending on the boiling point of methanol which is used during the transesterification. Fig. 1 showed that the biodiesel yield increases with rise in temperature upto $55^{\circ} \mathrm{C}$ and then falls down gradually. The yield of biodiesel at 35 and $55^{\circ} \mathrm{C}$ was about 43.7 and $74.6 \%$, respectively obtained after $50 \mathrm{~min}$ of reaction duration. The possible reason behind this trend is that with an increase in temperature, the viscosity of algae oil decreases resulting in the better contact area of the oil and methanol to react. Moreover, glycerol formed separates out faster at high temperature, which increases the rate and thus, higher biodiesel yield is achieved. However, a substantial drop in the yield of biodiesel was observed when the reaction temperature was raised above $55^{\circ} \mathrm{C}$. This could be due to the side reactions (such as: hydrolysis of FAMEs to respective acid and alcohol) which are favoured at very high temperatures and proceed at a higher rate in comparison to transesterification, thereby lowering the yield. The similar trends were observed while investigating the biodiesel production from Spirulina algae oil.

Effect of stirring intensity: The effect of stirring intensity of reactants during in situ transesterification on the yield of biodiesel from wastewater algae was examined by varying the intensity rate from 150 to $750 \mathrm{rpm}$. The change in the yield of biodiesel with increase in the intensity of stirring is shown in Fig. 2. The stirring increases the contact surface area in between the two reactants which would be otherwise in contact only via interface of the two phases of liquid. Stirring leads to an increase in reaction rate by homogenizing the reactants as a single phase and increases the biodiesel yield [12]. The trend shows that with the rise in intensity from 150 to $450 \mathrm{rpm}$, there is rise in the yield as well and thereafter it comes to equilibrium with further advancement of stirring intensity. The similar trends were observed while investigating the biodiesel production from Spirulina algae oil. 


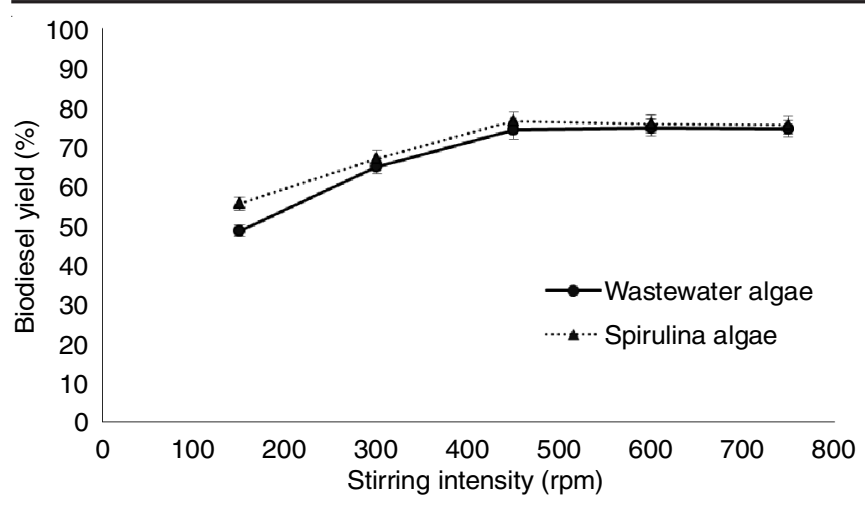

Fig. 2. Effect of stirring intensity in rpm on yield of biodiesel from algae $\left[55{ }^{\circ} \mathrm{C}\right.$ temperature, $60 \mathrm{wt}$. \% concentration of catalyst, 1:4 algae biomass:methanol (wt:vol)]

Effect of catalyst concentration: Fig. 3 shows the effect of change in the catalyst concentration from 25 to $100 \%$ (of dry algae biomass) on biodiesel yield. The catalyst used in the reaction was conc. $\mathrm{H}_{2} \mathrm{SO}_{4}$ because the acidic catalysts are reported in literature to be effective for maximum conversion of triglycerides and FFA present in algae oil to biodiesel [13]. It is observed that with increase in catalyst concentration from 25 to $60 \%$, the yield of biodiesel yield was also increased upto $74 \%$. However, increasing the concentration of catalyst from 60 to $75 \%$, a decrease of biodiesel yield to $68.40 \%$ was observed which dropped drastically to $38 \%$ when the catalyst concentration was increased to $100 \%$. The cause for the trend obtained could be that at high concentrations of catalyst, there is stimulation of the side reaction of triacylglycerides, resulting in low percentage of triacylglycerides available for biodiesel production and thus, decreases the overall biodiesel yield [14].

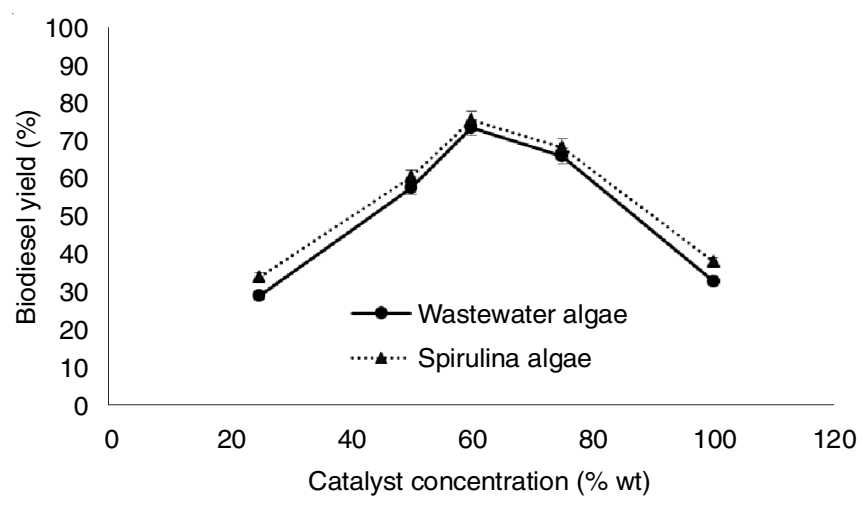

Fig. 3. Effect of concentration of catalyst on the yield of biodiesel from algae $\left[55^{\circ} \mathrm{C}\right.$ temperature, $450 \mathrm{rpm}$ stirring intensity $1: 4$ algae biomass:methanol (wt:vol)]

Effect of algae biomass to methanol ratio: The optimal quantity of methanol required in the transesterification reaction is an important factor, since it is responsible in deciding the yield of biodiesel. The methanol if taken in fewer amounts will adversely affect the conversion rate of triacylglycerides to biodiesel, whereas if taken in higher quantities, will lead to emulsification and thus reduce the biodiesel yield. Methanol contains polar hydroxyl group which emulsifies with glycerol as well as with biodiesel which is produced during the transesterification reaction thus, promoting the reaction to proceed in backward direction i.e. recombination of biodiesel and glycerol, and lower the yield of biodiesel [15]. Fig. 4 shows the trend of change in algae biomass:methanol (weight:volume) ratio from 1:1 to 1:6 in the reaction while keeping other reaction parameters constant. The initial increase in biodiesel yield from 54.80 to $74.40 \%$ was observed when the ratio of algae biomass: methanol was increased upto 1:4 and thereafter, increasing the ratio from 1:4 to $1: 6$, the biodiesel yield decreased to $71.90 \%$.

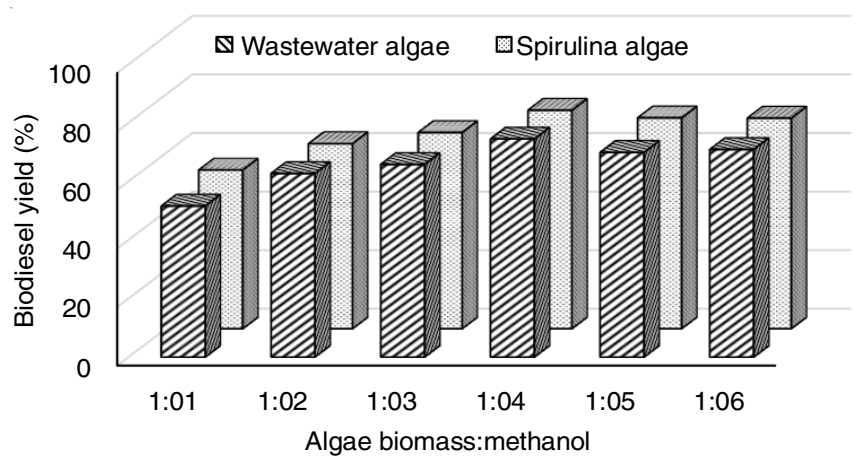

Fig. 4. Effect of ratio of algae biomass:methanol on the yield of biodiesel $\left[55^{\circ} \mathrm{C}\right.$ temperature, $450 \mathrm{rpm}$ stirring intensity, $60 \mathrm{wt}$ \% concentration of catalyst]

\section{Conclusion}

The production of biodiesel from wastewater algae biomass using in situ single stage transesterification strategy has been investigated in present study. The results of classical method of optimization of process parameters for simultaneous oil extraction and transesterification showed that the most suitable conditions for maximum algae biodiesel yield were: $55{ }^{\circ} \mathrm{C}$ reaction temperature, $450 \mathrm{rpm}$ stirring intensity, $60 \%$ catalyst concentration and 1:4 algae biomass to methanol ratio. Henceforth, it can be concluded that the wastewater algae biomass has the immense potential to be the alternate feedstock for biodiesel production with its effective utilization in diesel engine, which is comparable to other established biodiesel and diesel. Some areas, such as algae cultivation and biomass availability, have received certain criticisms concerning with the financial viability of algae biodiesel. The factors questioning its sustainability can be reversed by using low cost algae biomass such as algae growing in wastewater or natural water biodiesel $[16,17]$. This study positively established the viability of wastewater algae biomass as a feedstock to be used for the production of biodiesel which is having a hopeful potential as a substitute to petro-diesel.

\section{ACKNOWLEDGEMENTS}

One of the authors, P.N. thanks Council of Scientific and Industrial Research, New Delhi, India for graduate fellowship.

\section{CONFLICT OF INTEREST}

The authors declare that there is no conflict of interests regarding the publication of this article.

\section{REFERENCES}

1. J.M. Marchetti, V.U. Miguel and A.F. Errazu, Renew. Sustain. Energy Rev., 11, 1300 (2007);

https://doi.org/10.1016/j.rser.2005.08.006.

2. A. Demirbas, Energy Convers. Manage., 50, 14 (2009); https://doi.org/10.1016/j.enconman.2008.09.001. 
3. P. Nautiyal, K.A. Subramanian and M.G. Dastidar, Clean Technol. Environ. Policy, 19, 1667 (2017); https://doi.org/10.1007/s10098-017-1355-8.

4. K.T. Tan, K.T. Lee, A.R. Mohamed and S. Bhatia, Renew. Sustain. Energy Rev., 13, 420 (2009);

https://doi.org/10.1016/j.rser.2007.10.001.

5. S. Taravus, H. Temur and A. Yartasi, Energy Fuels, 23, 4112 (2009); https://doi.org/10.1021/ef900211n.

6. J. Huang, Y. Wang, J.B. Qin and A.P. Roskilly, Fuel Process. Technol., 91, 1761 (2010); https://doi.org/10.1016/j.fuproc.2010.07.017.

7. S.V. Ghadge and H. Raheman, Bioresour. Technol., 97, 379 (2006); https://doi.org/10.1016/j.biortech.2005.03.014.

8. Y. Chisti, Biotechnol. Adv., 25, 294 (2007); https://doi.org/10.1016/j.biotechadv.2007.02.001.

9. T.M. Mata, A.A. Martins and N.S. Caetano, Renew. Sustain. Energy Rev., 14, 217 (2010)

10. P. Nautiyal, K.A. Subramanian and M.G. Dastidar, Fuel Process. Technol., 120, 79 (2014); https://doi.org/10.1016/i.fuproc.2013.12.003.
11. P. Nautiyal, K.A. Subramanian and M.G. Dastidar, Fuel, 135, 228 (2014); https://doi.org/10.1016/i.fuel.2014.06.063.

12. F. Ma, L.D. Clements and M.A. Hanna, Bioresour. Technol., 69, 289 (1999); https://doi.org/10.1016/S0960-8524(98)00184-9.

13. B.D. Wahlen, B.A. Barney and L.C. Seefeldt, Energy Fuels, 22, 4223 (2008); https://doi.org/10.1021/ef800279t.

14. D.Y. Leung, X. Wu and M.K.H. Leung, Appl. Energy, 87, 1083 (2010); https://doi.org/10.1016/j.apenergy.2009.10.006.

15. H.J. Kim, B.S. Kang, M.J. Kim, Y.M. Park, D.-K. Kim, J.-S. Lee and K.-Y. Lee, Catal. Today, 93-95, 315 (2004); https://doi.org/10.1016/j.cattod.2004.06.007.

16. P. Nautiyal, K.A. Subramanian and M.G. Dastidar, J. Environ. Manage., 182, 187 (2016); https://doi.org/10.1016/j.jenvman.2016.07.063.

17. P. Nautiyal, K.A. Subramanian and M.G. Dastidar, Environ. Process., 4(S1), 179 (2017);

https://doi.org/10.1007/s40710-017-0230-2. 